\title{
Las bambalinas de la comedia textual*
}

\author{
Nicolás GARAYALDE \\ Universidad Nacional de Córdoba \\ negarayalde@gmail.com \\ ORCID: 0000-0002-0692-4330
}

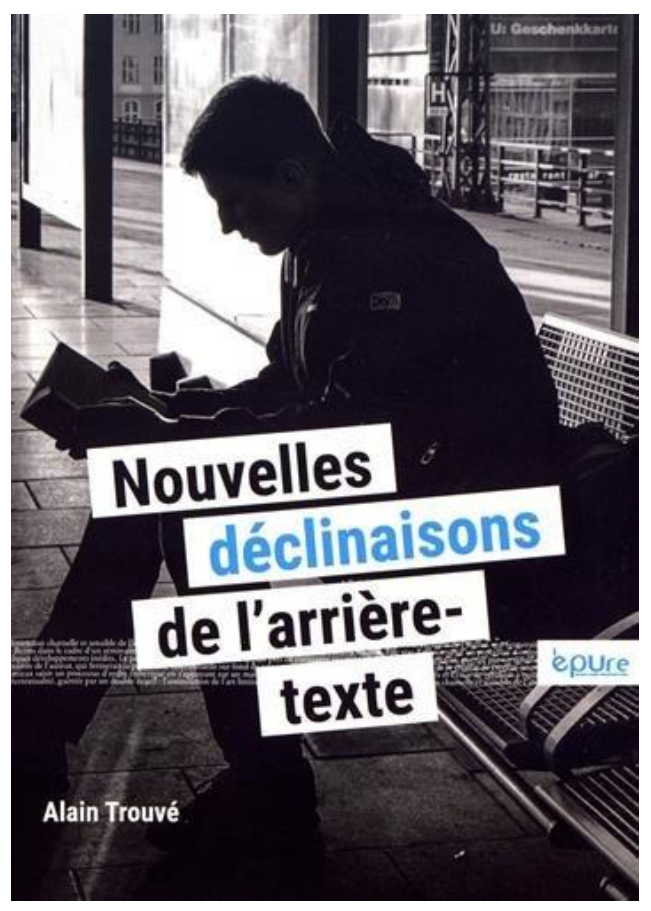

Quizás haya pocos conceptos en la historia de los estudios literarios con tanta fortuna como el de texto. Si no fuera por el alcance negativo de la metáfora, no escatimaría en hablar de un verdadero imperialismo conceptual cuyo poder de conquista radica en una proliferación de neologismos acuñados a lo largo de los últimos sesenta años por una diversidad de teóricos literarios, en su mayoría franceses.

Inaugurado por Julia Kristeva a partir del problema de la intertextualidad (del que emergería el intertexto y al que añadiría, tiempo después, los conceptos de geno-texto y feno-texto) y secundado por una serie fascinante que desfila en las páginas de los prolíficos ensayos de Gérard Genette (hipotexto, hipertexto, transtexto, paratexto, architexto), un singular gesto teórico emergió desde entonces en nuestro campo disciplinar. Gesto que, ni lento ni perezoso, supo hacer uso de la generosidad de los prefijos y ofreció al concepto de texto un derrotero extenso y variopinto, ensanchando la lista de los neologismos anteriores: autotexto (Lucien Dällenbach, 1976), contra-texto (Anne Clancier, 1977), infratexto (Jean Bellemin-Noël, 2001) e incluso -aunque más no haya sido sino a modo de ejemplo y en el contexto de un ensayo dedicado a enseñar cómo hacer teórica literaria-anatexto, catatexto, antitexto y, mi favorito, cistexto (Sophie Rabau y Florian Pennanech, 2016). En cierta ocasión, yo mismo he pro-

\footnotetext{
* Acerca del libro de de Alain Trouvé, Nouvelles déclinaisons de l'arrière-texte (Reims, Épure, 2018, 88 p. ISBN: 978-2-37496-056-2).
} 
puesto humildemente -aunque la falta de creatividad me haya conducido a un término grandilocuente- la noción de hipercontratexto. Franc Schuerewegen (2012), por su parte, ha tenido la osadía de elaborar una teoría postextual que, irreverente con la explication du texte todavía presente en la enseñanza media francesa en la época en que el posestructuralismo comenzaba a desarmarlo todo, parecía enmarcarse hace poco tiempo en una renovación paradigmática de los estudios literarios franceses que ha asumido el nombre de la teoría de los textos posibles.

Aquí y allá, pues, la familia textual desplegó un árbol genealógico de la talla de los Rougon-Macquart. Por supuesto, podría verse allí el exceso de un entusiasmo desmesurado que nació ante el cuestionamiento a la concepción orgánica de las obras y procuró acompañar el anhelo -presente en Roland Barthes (2002a)de una ciencia de la literatura que se formularía pronto como una ciencia del texto (que podríamos llamar hifología, según el término propuesto por el propio Barthes para referirse a una teoría del texto). Sin embargo, nada sería más injusto que tal suposición, pues la proliferación de nociones que orbitaron, complejizaron o procuraron reemplazar aquella de texto es el síntoma más cabal de una conciencia heredera también de Barthes- de la imposibilidad de delimitar un objeto que sirva a la configuración de una ciencia, en la medida en que fracturó sus límites, expuso su inasible movilidad y configuró un complejo problema epistemológico: ¿cómo construir un objeto de los estudios literarios que se presenta por definición plural, relativo y posterior -antes que anterior- a su lectura?

Cada uno de los conceptos que emergieron en el marco de esta comedia textual procuró resolver las distintas dificultades que este interrogante presentó. La intertextualidad, recuperando un descubrimiento ya presente en el modelo de los sistemas de Iuri Tinianov (2008), no sólo puso en jaque la noción misma de obra como una mónada autónoma sino que buscó además configurar un nuevo objeto basado en las relaciones textuales. Sin embargo, en una época en que la teoría literaria veía aparecer una serie de modelos orientados a la lectura y modificaba así, epistemológicamente, el estatus del objeto, no tardaría en llegar la pregunta por los criterios de determinación que unen un texto con otro y por los papeles que toca en ello al autor y a los lectores. En este sentido, Jean-Bellemin Noël (1994) propuso la noción de interlectura para dar cuenta de las asociaciones intertextuales evocadas a partir del proceso de lectura; tiempo después, en el mismo camino, Pierre Bayard (1996) hablaría de intertextualidad subjetiva al atribuir al lector relaciones entre los textos que no necesariamente estaban presentes en la mente del autor -llegando incluso, con su habitual ironía, a proponer relaciones de plagio por anticipado (Bayard, 2009). Incorporado el lector, a pocos pasos quedaba la pregunta por la naturaleza ontológica de los textos: no sólo si verdaderamente existen -Louis Hay (1985) llegaría a negarlos- sino sobre todo en qué momento vienen a la existencia; pues, cuestionada la potestad del autor, una serie de teóricos resolvieron lógicamente que el texto era un fenómeno posterior a la lectura, y no previa: Stanley Fish (1980) lo plantearía desde el pragmatismo; Anne Clancier (1977), desde el psicoanálisis; Michel Charles (1995), desde la retórica. 
Las dificultades de la flamante ciencia del texto, vinculadas a un objeto travieso y huidizo, ontológicamente problemático y epistemológicamente inasible, condujeron -desde el momento en que la noción de intertextualidad quebró los límites tranquilizantes de la obra-, a que la noción de texto acabara por cumplir en muchos casos el mismo papel que la sexualidad en el psicoanálisis, y pudiese recibir así una objeción semejante: la de pantextualismo. Cultura, historia (general, lingüística y literaria), autor, lector (y sus inconscientes): prontamente todos estos elementos fueron susceptibles de ser analizados como materialidades textuales que se entramaban a la entidad literaria, cada vez más incierta en sus límites, con la que el crítico se enfrentaba.

En este marco de problemas, deberíamos ubicar y ponderar uno de los últimos integrantes de la familia textual que se gestó en el seminario de investigación Approches Interdisciplinares de la Lecture, creado en 2005 en la Universidad de Reims: el arrière-texte. Presentado públicamente en 2010 en un libro colectivo del seminario (Intertexte et arrière-texte: les coulisses du littéraire) y en un artículo de Alain Trouvé (uno de los directores del seminario) que apareció en el número 164 de la revista Poétique ("L'arrière-texte. De l'auteur au lecteur"), la noción continuó siendo elaborada en otros dos trabajos colectivos (Déclinaisons de l'arrière-texte, 2012; L'arrière-texte: Pour repenser le littéraire, 2013) y, finalmente, en un libro de Trouvé aparecido en 2018 y sobre el cual nos interesamos particularmente aquí como modo no solo de reseñar su publicación sino también del concepto que lo ocupa: Nouvelles déclinaisons de l'arrière-texte.

En su brevedad, este libro logra condensar una rigurosa presentación del concepto de arrière-texte ensayando dar respuesta a la extensa problemática hifológica y partiendo astutamente de un movimiento que, sin dejar de atender la amplitud del universo textual, es capaz de ir más allá de sus límites y evitar la tentación de su extensión al universo. En esto, la analogía con el psicoanálisis se repite, pues el pantextualismo se resuelve mediante un más allá que recurre tanto a lo imaginario como a lo real del cuerpo, configurando una topología del texto literario que procura "articular" - palabra que subraya el propio Trouvé- las distintas dimensiones implicadas, con énfasis en las relaciones entre lo textual y lo notextual.

¿Qué es el arrière-texte? ¿En qué radica su riqueza conceptual? Trouvé lo define de la siguiente manera:

Tout ce qui se trouve en amont de la création littéraire, appréhendée selon ses deux versants auctorial et lectoral. On peut le concevoir comme le réseau d'associations présidant à l'effet littérature : associations verbales, sensorielles, cognitives, qui englobent et dépassent le phénomène d'intertextualité. [...] Arrière, dans son acception spatiale, évoque les travaux associant lecture et scénographie imaginaire, d'où l'image des «coulisses du littéraire ». [...] Le préfixe arrière comporte aussi un sens temporel d'antériorité applicable à la genèse de la création. Il possède enfin une valeur hiérarchique : l'arrière texte renvoie alors aux notions de la- 
tence, de présupposés culturels, d'étayage d'un texte sur un vécu, auctorial ou lectoral (pp. 7-8).

Esta definición exhibe ya la virtud del concepto en cuanto a su aporte a una teoría del texto, en la medida en que advertimos allí tres presupuestos que aglutinan una ya extensa tradición del pensamiento hifológico: 1) una concepción ontológica del texto que involucra tanto al autor como al lector (quitando al primero el absoluto privilegio de la "creación literaria"); 2) un posicionamiento que, resonando una perspectiva psicoanalítica, enfatiza lo que permanece latente, implícito, presupuesto -incluso inconsciente-, tanto a nivel individual como colectivo (social, lingüístico y cultural); 3) la incorporación de elementos que remiten a un más allá del texto (incluyendo lo imaginario, lo sensorial, lo corporal, lo vivido).

Es sobre todo en este último punto, a mi parecer, donde radica la novedad más interesante del concepto que desarrolla Trouvé, llamando la atención sobre aquello de la experiencia literaria que el pantextualismo invisibilizaba y que, dicho sea de paso, recupera un gesto del último Barthes cuando, describiendo las distintas fases de su pensamiento (de la mitología a la semiología, y de esta a la teoría del texto), pregona una "revendication du corps" (2002b: 650) y se inquieta por la petrificación del Texto. Por eso, es posible que la noción de arrière-texte hubiese gustado a ese Barthes de los años '70 - cada vez más atento a las dimensiones de lo imaginario y de lo real del lenguaje lacaniano.

En este sentido, no es casual que en Nouvelles déclinaisons de l'arrièretexte, Trouvé indague una tópica del arrière-texte en un capítulo dedicado a una reflexión sobre la pintura, donde la imagen expone el problema de su lectura en un más allá textual, haciendo emerger, en una bella afirmación, el fenómeno de lo ilegible: «La peinture exemplifie ou accentue la part d'indéchifrable de tout système sémiotique. Elle touche davantage à la primitivité et en ces sens à l'illisible » (34). El concepto se vuelve apasionante y novedoso, pues insta a pensar una tópica del afuera textual, apelando a una suerte de fenomenología de lo latente, de lo implícito, de lo indescifrable, del cuerpo y las circunstancias.

Por ello, coherentes con su prefijo -y los sentidos que aprovecha Trouvé-, deberíamos preguntar aquí no tanto qué es sino dónde es el arrière-texte, pues lo que explora es esa zona problemática en la que lo textual y lo no-textual se articulan, según una tópica que Trouvé desglosa en cuatro dimensiones: 1) el intertexto latente -que el autor había ya desarrollado en el número 9 de la revista La lecture littéraire, donde lo define como "un texte susceptible d'avoir impregné la mémoire de l'auteur mais dont l'écriture de l'œuvre nouvelle se détourne au point de paraître l'ignorer" (Trouvé, 2007: 167)-; 2) el trasfondo circunstancial (que configura el contexto que da lugar a la escritura: un espacio-tiempo en el que se juegan la experiencia y una forma de reencuentro con lo real); 3) el trasfondo cultural (que involucra el acervo de la lengua y su historia); 4) el cuerpo (como expresión de lo real que se liga al afecto).

Sin embargo, la noción de arrière-texte no detiene en esta tópica su complejidad, puesto que vienen a agregarse aquí otros dos aspectos más que la definen 
y que recuperan respectivamente la tradición psicoanalítica y las teorías orientadas al lector: lo dinámico y lo extensivo.

El primero de ellos sirve a Trouvé no sólo para introducir la dimensión de lo inconsciente en la experiencia literaria pensada desde el punto de vista del arrière-texte, sino también a revisar los modos de articulación entre el psicoanálisis y la literatura (deslizando una interesante crítica a lo que se podría llamar el psicoanálisis aplicado). Las bambalinas del texto son por lo tanto trabajadas aquí a partir de una articulación entre el mundo interno y el externo del escritor, reubicando la metáfora espacial en las coordenadas winnicottianas del espacio transicional y potencial. Sin embargo, no es el inconsciente del autor el único implicado -como no es la creación del texto su privilegio absoluto. Pues Trouvé, atento a los debates del campo de los estudios literarios, introduce la extensión como tercer aspecto del arrière-texte.

Si los límites del textos se indagaban en la tópica en un más allá del significante y en la dinámica en un más allá de lo consciente, la extensión apela a un más allá de lo autoral, incorporando una dimensión temporal del texto, en la medida en que se configura entre dos escenas en el marco histórico de la vida literaria: «à l'arrière-texte auctorial reconstitué, toujours de façon fragmentaire, il convient en effet d'ajouter un arrière-texte lectoral potentiellement identifiable par d'autres lecteurs » (p. 16). Es particularmente interesante que en Nouvelles déclinasons de l'arrière-texte el último capítulo dedicado a la extensión se detenga un buen momento en la lectura derrideana de Platón, porque se trata no sólo de considerar la vertiente lectoral en la experiencia literaria sino también de ponderar los motivos por los cuales la construcción del texto escapa al poder del autor por razones que competen a la escritura: « le sujet écrivant n'est pas entièrement maître de sa parole. La production de l'œuvre est adossée à l'arrière-boutique obscure de l'écriture : espace mental d'une transaction, bric-à-brac appréhendé dans une semi-conscience » (p. 72).

El arrière-texte se presenta así como una conceptualización que define una topología del texto de la trastienda: del espacio no-textual (tópica), del espacio inconsciente (dinámica), del espacio lectoral (extensiva); configura por lo tanto un entramado teórico que aglutina una reflexión de los márgenes que, sin abandonar el anhelo de una Ciencia del Texto, se desliga de la amenaza pantextualista incorporando aquello que una prolífica familia textual (prolífica precisamente por la dificultad de aprehender un objeto tan vasto como inasible) había dejado de lado: la trastienda, las bambalinas, la experiencia fuera-de-texto, el tras-texto. Basta detenerse en las antologías críticas que este concepto ha dado lugar para advertir su riqueza, su potencialidad y su necesidad en la teoría literaria contemporánea.

\section{REFERENCIAS BIBLIOGRÁFICAS}

BARTHES, Roland (2002a): Le plaisir du texte. CEuvres complètes, T. IV. París, Seuil. BARTHES, Roland (2002b): Roland Barthes par Roland Barthes. Euvres complètes, T. IV. París, Seuil. 
BAYARD, Pierre (1996): Le hors-sujet. Proust et la digression. París, Minuit.

BAYARD, Pierre (2009): Le Plagiat par anticipation. París, Minuit.

BELLEMIN-NoËL, Jean (1994): «De l'interlecture », in Michel Picard (ed.), Comment la littérature agit-elle ? París, Klincksieck, 147-165.

BELLEMIN-NOËL, Jean (2001): Plaisirs de vampire. París, PUF.

CHARLES, Michel (1995): Introduction à l'étude des textes. París, Seuil.

ClancIER, Anne (1977): «Qu'est-ce qui fait courir Boris Vian ? », in Noël Arnaud y Henri Baudin (eds.), Boris Vian, Colloque de-Cerisy-La-Salle. Paris, UGE, 49-86.

DÄlLENBACH, Lucien (1976): «Intertexte et autotexte ». Poétique, 27, 282-296.

FisH, Stanley (1980): Is There a Text in This Class? The Authority of Interpretative Communities. Cambridge, Harvard University Press.

GENETTE, Gérard (1982 [1979]): Introduction à l'architexte. París, Seuil.

GENETTE, Gérard (1982): Palimpsestes, la littérature au second degré. París, Seuil.

GLADIEU, Marie-Madeleine \& TROUVÉ, Alain [dir.] (2010): Intertexte et arrière-texte: les coulisses du littéraire. Reims, Épure.

Gladieu, Marie-Madeleine \& Alain Trouvé [dir.] (2012): Déclinaisons de l'arrièretexte. Reims, Épure.

GladIEU, Marie-Madeleine \& Alain TrouvÉ [dir.] (2013): L'arrière-texte: Pour repenser le littéraire. Bruxelles, Peter Lang.

HAY, Louis (1985): «Le texte n'existe pas. Réflexions sur la critique génétique ». Poétique, 62, 147-158.

RABAU, Sophie \& Florian PENNANECH (2016): Exercices de théorie littéraire. París, Presses Sorbonne Nouvelle.

SCHUEREWEGEN, Franc (2016): Introduction à la méthode postextuelle. París, Garnier.

TINIANOV, Juri (2008): « Sobre la evolución literaria », in Tzvetan Todorov (ed.), Teoría de la literatura de los formalistas rusos. Buenos Aires, Siglo XXI, 123-143.

TrouvÉ, Alain (2007): «Sur les traces de l'intertexte latent », in Alain Trouvé (ed.), La lecture littéraire, 9 [Lecture et psychanalyse, Reims. CRLELI], 163-177.

TrouvÉ, Alain (2010): «L'arrière-texte. De l'auteur au lecteur». Poétique, 164, 495509. 